\title{
Design of University Central Kitchen Management Information System
}

\author{
Quanzhou Huang \\ School of Computer Science, Xi'an Shiyou University, Xi'an, Shaanxi, 710065, China \\ qzhuang@xsyu.edu.cn
}

Keywords: Central Kitchen; Food orders; Logistics and distribution management; Work flow

\begin{abstract}
With the increasing enrollment of colleges and universities, the demand for catering services is getting higher and higher. The traditional management mode has not adapted to the development of the new situation, so it is urgent to reform the management mode. This paper analyzes the shortcomings of traditional college food management mode and introduces the concept, factors and characteristics of the central kitchen management mode. Combining the central kitchen management mode with information technology, the management information system based on central kitchen mode is proposed. The realization scheme and technical route of the system are discussed. The software structure, data model and workflow of the system are designed. The construction of the college center kitchen and its management system will greatly promote the improvement of its management level and better serve the teachers and students.
\end{abstract}

\section{Introduction}

The university catering center is the key of the university's logistics, and the logistics management of universities is an important part of higher education in China. It is a kind of guarantee, constructive and basic work[1,2].The reform of the canteen management mode and the transformation of the Canteen business mode is an important part of the social reform of the college canteens. The difficulty, emphasis and hot spot of logistics reform in colleges and universities are catering servic work.

Colleges and universities provide catering services to thousands of students and teachers every day.In the traditional management mode, the university dining center establishes several canteens, each of which is independent food processing and marketing enterprises. Every canteen is equipped with many cooks, waiters and administrators, and needs to purchase a large number of food processing equipment and environmental protection facilities.Every canteen does the same work every day, doing the same tasks, resulting in a lot of human and resource waste[3,4].

In order to meet the needs of modern management, enterprises need to improve the workflow, integrate resources, improve the production efficiency, reduce waste[1]. Based on this, the advanced kitchen center management mode is introduced into the logistics management of universities and combined with information technology, workflow technology and logistics technology to improve the management level. This is a new type of production and management mode[3,5]

The center kitchen is a modern food production base, equipped with complete environmental protection equipment, food processing equipment and skilled technical workers. From Ordering of raw materials, food production to food sells, the center kitchen may carry out unified management. The canteens product foods no longer, but merely sell foods. Canteens order foods from the center, the center kitchen products and distribute foods, logistics management department inspects all the work flows and productaion procdures.

The new model has many advantages, compared to traditional model. It may save resources, improve the working efficiency, avoid the repetitive construction and investment, and also facilitate focused on quality management and supervision[2,5]. Central kitchen implements five unity, including: unified purchase, unified order, unified distribution, unified regulation and settlement[6,8].

Based on information technology and workflow technology, this paper mainly discusses the main technology of central kitchen management information system and its applications. 


\section{Central kitchen Management Mode}

Central kitchen also known as central kitchen or distribution center.The main task is to make the raw materials into semi-finished products or finished products by orders, and then distribute them to the canteen for secondary processing or direct sales to customers[3,4].

It consists of raw materials testing center, food, clean workshop, machining workshop, material warehouse disinfection workshop, distribution center, etc, has realized the unified purchase, unified examination, processing and distribution. The central kitchen realizes the standardization and modernization of management, and guarantees the quality, hygienic and safe catering service for the consumers.

Its specific operation procedure is: the canteens choose the foods that needs to form the orders, the kitchen center produces finished or semi-finished products according to the orders, the logistics and distribution center deliver foods to the canteens according to the orders, the canteens are mainly responsible for sales.

The central kitchen has three advantages: one is to reduce the production cost, the second is to ensure the quality of food, and the third is to facilitate inspection and management.

Its main functions: centralized purchasing functions, production processing functions, inspection functions, uniform packaging functions, frozen and storage functions, transportation and distribution functions, orders information processing functions.

The relationship between the canteens, consumers,kitchen enter and management department is shown in figure 1.

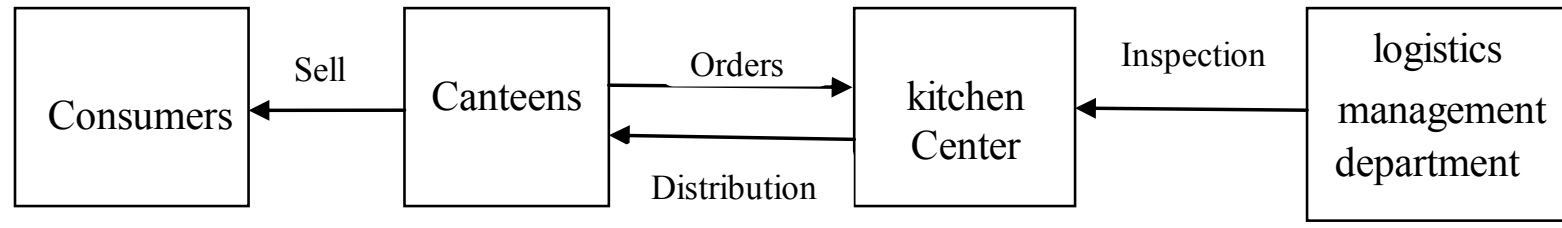

Figure 1. Business relationship diagram

\section{Central kitchen Management System Design}

System overall architecture. The college central kitchen management system is a complex system engineering.It is composed of multiple subsystems, including order management system, logistics management system, human resource management system, equipment management system, purchasing management system, inventory management system, financial management, quality control system, etc. There are complex workflows between each other. Among them, order and logistics management system is the most basic, this paper mainly studies the implementation plan and workflow of the order and logistics management system.

The system is developed in $\mathrm{B} / \mathrm{S}$ mode. The system is divided into two parts by transaction type: canteens module as front desk and central kitchen management module as background. Orders management and financial magement are the key of the system. System software architecture diagram is shown in Fig. 2.

Order work flow.

(1) First users login system according to password.

(2) Canteen users browse foods list, and choose foods

(3) The orderer fill in the orders form,including various information about the orders.

(4) The orderer may modify the orders before submission.

(5) The orderer formally submits the orders.

(6) Central kitchen users may view the orders and send the orders to production department and distribution department.

(7) Central kitchen users may sum the orders according to the food types, produce summary orders table every day.

(8) Deliveryman delivery goods to the canteens on time according to the orders. 
(9) Deliveryman may fill in the delivery information.

(10)The end of every month will do financial statistics and accounting for all canteens according to the orders.

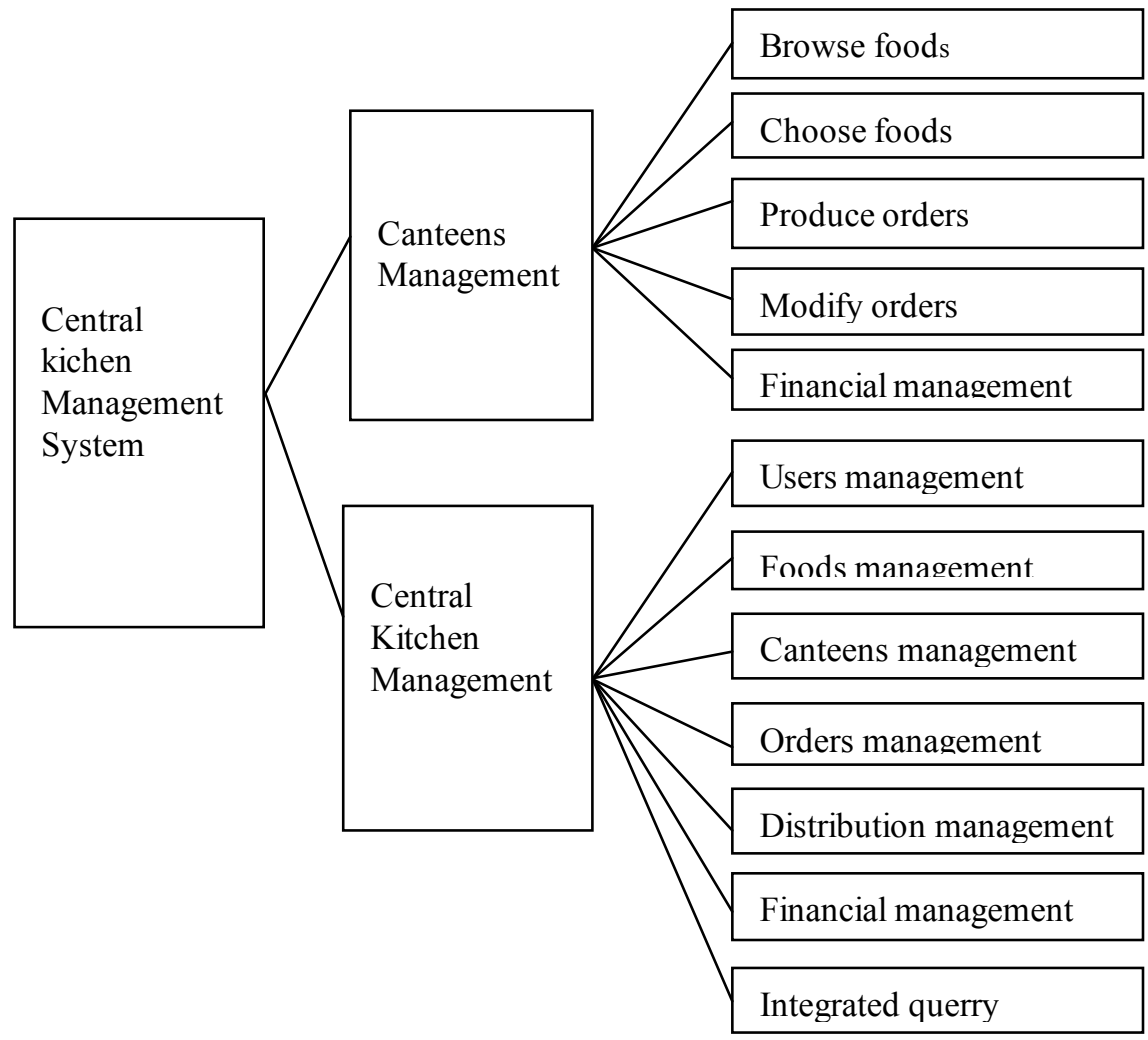

Figure 2. The software structure diagram

Database design. Database design is an important work in the system design, it must comply with the principle of database design[3,4,9]. The main work of the system is order and logistics management.The database server is located on the backend server and consists of multiple data tables. Each table has its own primary and foreign keys. The main database includes user information table, Foods information table, Canteens information table, Orders and distribution information table, Order details table, etc. The relationship between the tables is shown in figure 3 .

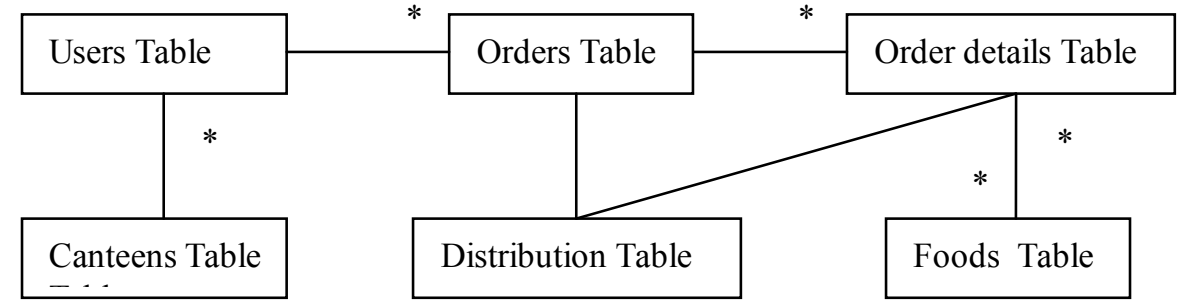

Figure3. Entity relationship diagram between tables

System implementation. System network structure is shown in Fig. 4. The central kitchen, restauants and data center(database server) link together by the campus network. All the data is stored in database server of the data center for sharing. Users use the logistics management software to complete all kinds of tasks.

The system is based on a Java development platform. It uses JSP technology and SQL-Server database. Using object-oriented method and UML to analysis, design and modeling, the software system has a good structure, extensibility, and a friendly interface $[8,9,10]$. After system testing, it has reached the design goals. 


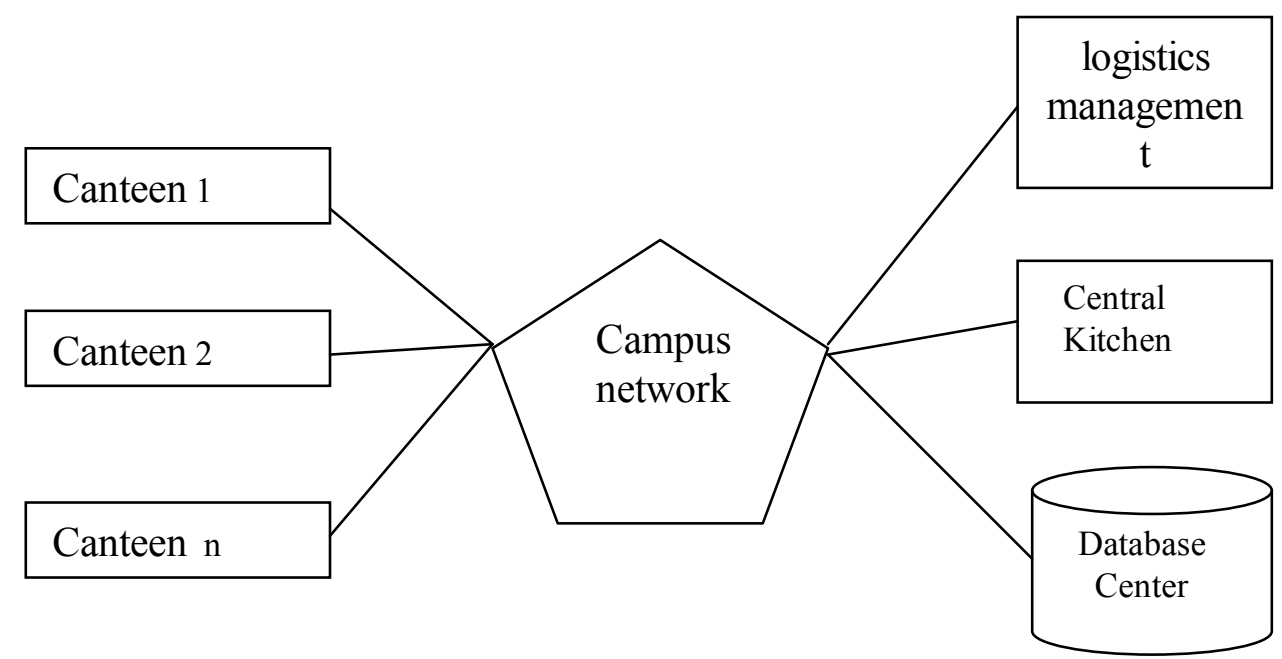

Figure 4. System network sturcture diagram

\section{Summary}

Based on the above design, we developed the corresponding software system. After verification, the system can completely meet the needs of users. The implementation scheme proposed in this paper is completely feasible, and the software structure design and data model design are also correct. Combining the central kitchen mode with information technology can greatly improve production efficiency, save resources, reduce costs and enhance enterprise competitiveness. The paper focuses on the implementation of the order and logistics management system, and the next step is to study the workflow of other subsystems and develop corresponding software system.

\section{References}

[1] X.M. Ma: Logistics and Technology, Vol. 30(2011) No. 9, P.88. (In Chinese)

[2] L.M. Mu and G.F. Liu: Computer Applications and Software, Vol. 27(2010) No. 8, P.79. (In Chinese)

[3] H.J. Zhou: Jilin University, Vol. 23(2009) No. 2, P.35-38. (In Chinese)

[4] H. Chen and Y.T. Xi: Geomatics \& Spatial Information Technology, Vol. 33(2010) No. 3, P48. (In Chinese)

[5] J. Shen: Automation Instrumentation, Vol. 33(2012) No.1, P12. (In Chinese)

[6] W.L.Su, S.Ye and Z.Y. Zhang: Computer Knowledge and Technology, Vol. 8(2012) No. 16, P3869. (In Chinese)

[7] Information on http://www.docin.com/p-1467558646.html

[8] Information on https://wenku.baidu.com/view/d01b3658804d2b160b4ec03e.html

[9] R.S.Pressman: Software Engineering: A Practitioner's Approach (Mechanical Industry Press, China 2010). (In Chinese)

[10] I. Jacobson: The Unified Software Development Process (Mechanical Industry Press, China 2012). (In Chinese) 